\title{
LETRAMENTO POLÍTICO: TRILHAS ABERTAS EM UM CAMPO
} MINADO

Rildo Cosson ${ }^{1}$

\begin{abstract}
Resumo: Considerando a educação política um campo amplo e multifacetado, propõe-se estreitar seu escopo ao letramento político definido como o processo de apropriação de conhecimentos (direitos humanos, instituições políticas, democracia), práticas (exame de temas controversos, participação decisória, diálogo) e valores (equidade, liberdade) para a manutenção e o aprimoramento da democracia. A partir dessa definição e com o objetivo de fomentar um debate mais profícuo do tema, apresentam-se posições relativamente consensuais entre os estudiosos da área sobre os conteúdos, as práticas e as condições necessárias para o sucesso do ensino da democracia.
\end{abstract}

Palavras-chave: letramento político, educação para democracia, educação para cidadania, educação política

Abstract: Considering the political education a broad and multifaceted field, it is proposed to narrow its scope to the political literacy that it is defined as the process of appropriation of knowledge (human rights, politic institutions, democracy), practices (controversy issues exam, share decisions, dialogue) and values (equity, freedom) to the support and improvement of democracy. Based on this definition and in order to foster a more productive debate of the issue, it is presented consensual positions among scholars of the area over the content, practices and conditions necessary for successful teaching of democracy.

Keywords: political literacy, civic education, education for democracy, citizenship education

\footnotetext{
${ }^{1}$ Coordenador do Programa de Pós-Graduação do Centro de Formação, Treinamento e Aperfeiçoamento (Cefor) da Câmara dos Deputados e pesquisador do Centro de Alfabetização, Leitura e Escrita (Ceale) da Faculdade de Educação da UFMG (rildo.mota@camara.gov.br)
} 
Democracia não funciona no piloto automático. Afortunadamente, nós já sabemos como fazer muito do que precisa ser feito. O que nos falta correntemente é um compromisso educacional adequado com a democracia. (Kahne e Westheimer, 2003²).

\section{Introdução}

$\mathrm{Na}$ abertura de um estudo em que analisam vários programas de letramento político nos Estados Unidos, Kahne e Westheimer (2003) incitam o leitor a identificar o que seria notícia em relação a uma escola: a incapacidade de ensinar conhecimentos matemáticos e desenvolver a habilidade de leitura ou sua incompetência na formação de cidadãos democráticos. Para os autores, não há dúvidas que apenas a primeira possibilidade que trata do desenvolvimento das competências intelectuais básicas alcançaria o status de manchete. A resposta pressuposta, argumentam, mostra que o ensino da democracia ainda é considerado uma questão de segunda ordem quer para as escolas, quer para o governo que lhes reserva porcentagens ínfimas no orçamento e praticamente ignora o tema nos testes oficiais de competência intelectual. Dessa forma, apesar de todo o discurso que se tem sobre a importância da educação para manter e fortalecer a democracia, a maioria das escolas toma o tema exatamente como apenas um discurso, ou seja, um ato retórico, sem sustentação e sem necessidade de prática.

Entre nós, a situação não parece ser muito diferente, agravada pelo histórico pouco recomendável dos anos 1970, com as disciplinas Educação Moral e Cívica, Organização Social e Política Brasileira, e Estudos de Problemas Brasileiros, conforme se distribuíam do ensino fundamental ao nível superior. Como bem destacam Vanessa Kern de Abreu e Geraldo Inácio Filho, "a moral e cívica, antes de ser uma disciplina escolar relacionada à fragmentação do ensino de história, (...), foi concebida como uma doutrina direcionada do Estado [ditatorial] e voltada para os fins buscados por ele próprio" (2006, p. 133).

Além disso, ao contrário dos Estados Unidos, onde a expressão "civic education" goza de relativo consenso, não temos uma expressão dominante para a relação entre educação e política. Na verdade, temos um campo semântico constituído de muitos termos, recortando, recobrindo e repartindo abordagens e práticas nem sempre compatíveis umas com as outras: educação política, educação para cidadania, educação para a democracia, educação para cidadania democrática, educação em direitos humanos, educação comunitária, educação para a cidadania global, educação para paz, educação para a diversidade ou educação para a cidadania multicultural e letramento político. Para cada uma dessas expressões, é possível mapear conceitos e metodologias, afora os espaços e os contextos de uso que lhes são subjacentes, entre outros aspectos, indicando com a sua adoção a diferença que se deseja destacar frente às outras denominações. É assim que, quando se fala em educação para os direitos humanos, o foco é, obviamente, na Declaração Universal dos Direitos Humanos, e o seu núcleo de atuação se volta

\footnotetext{
${ }^{2}$ Todas as traduções do inglês são nossas.
} 
menos para as questões políticas da cidadania ou da democracia e mais para "a formação de uma conduta ética e solidária" (Carvalho et al., 2004, p. 435) fundada em uma educação de valores, como se observa na proposta do curso de formação de professores com o objetivo de difundir ideais e valores dos direitos humanos, da democracia e da cidadania oferecido no Projeto Direitos Humanos e Cidadania nas Escolas (Carvalho et al., 2004). Do mesmo modo, quando se adota a expressão educação comunitária, a ênfase recai sobre as maneiras de se tornar "os recursos da cidade e, prioritariamente, do entorno da escola, como espaços de aprendizagem, promoção e garantia de direitos" (Araújo, p. 2007, p. 6), conforme a concepção de cidade educadora, mesmo que as ações sejam "permeadas o tempo todo por temáticas de ética, direitos humanos, convivência democrática e inclusão social" (idem, p. 10).

A perspectiva que se vai adotar para este ensaio é a do letramento político. Nossa preferência pelo termo, já explicitada alhures (Cosson, 2008), vem da possibilidade de se trocar 'educação', um termo muito amplo, por um mais específico e de circulação recente no Brasil, que é o letramento. Depois, apesar de ser usada regularmente nos países de língua inglesa pelo menos desde os anos 1950, a expressão letramento político ganhou novos contornos ao ser definida por Bernard Crick, quando propõe a criação de uma disciplina para o ensino da democracia nas escolas inglesas, como "não apenas o conhecimento das instituições e ideias políticas e sociais, mas também as habilidades, os valores e atitudes que são necessárias para a prática da boa cidadania na vida adulta" (Crick, 1998, p. 64). Finalmente, recebendo contribuições das novas leituras sobre o letramento no campo educacional e do seu uso mais recente no mundo inglês, a expressão letramento político permite que se imprimam na nova denominação aspectos relevantes que não são possíveis nos termos anteriores, como é o caso de processo e apropriação, ao lado da incorporação de elementos mais operacionais em sua definição, o que acontece com a explicitação de práticas, conhecimentos e valores necessários para a sustentação da democracia.

Dessa forma, tomando o letramento político como "o processo de apropriação de práticas, conhecimentos e valores para a manutenção e aprimoramento da democracia" (Cosson, 2010, p. 30), propomos apresentar aqui reflexões de pesquisadores reconhecidos em três grandes questões - o que ensinar, como ensinar e as condições necessárias para o desenvolvimento dessa educação - que podem ajudar a fundamentar uma pedagogia do letramento político dentro e fora da escola.

\section{Letramento político: o que ensinar}

O conteúdo que se supõe necessário ao letramento político é geralmente relacionado ao funcionamento do estado, com ênfase para os mecanismos democráticos, o que envolve, por um lado, um conhecimento sobre eleições, partidos e instituições, e, por outro, os direitos e deveres 
dos cidadãos. Trata-se, pois, em termos sintéticos dos conhecimentos sobre como a distribuição de poder se organiza e funciona em uma sociedade democrática. Não surpreende, portanto, que uma boa parte dos cursos e programas de letramento político tome a Constituição ou a Declaração dos Direitos Humanos como uma referência básica para os conhecimentos a serem ensinados. Ao tratar da formação ética e cidadã nas escolas, José Sérgio Carvalho (2002), por exemplo, sinaliza em nota final que os valores morais e princípios dessa formação podem ser encontrados na Constituição.

O uso desses e outros documentos como conteúdo, entretanto, costuma ser criticado pelo caráter meramente formal e informativo que tal ensino pode adquirir. Nesse caso, como Carvalho destaca, em outro texto, "a educação de valores fundamentais à vida pública não pode consistir meramente na transmissão de informações, tais como o conteúdo da Declaração dos Direitos do Homem ou os princípios da Constituição da República", mas sim em práticas efetivas que não podem ser restritas a uma disciplina ou curso, pois "a posse dessas informações pode desempenhar um papel fundamental na elaboração de conceitos e práticas vinculados à educação para cidadania. Mas sua mera tematização não garante uma ação educativa vinculada a esses valores" (Carvalho et al., 2004, p. 435).

Além disso, como argumentam os defensores da educação para a cidadania global e da educação para a cidadania multicultural, o letramento político não pode ficar restrito aos limites nacionais dados pela Constituição, sob o risco de se prender a paroquialismos, perdendo de vista contextos sociais, políticos e econômicos mais amplos. Nem restrita a uma visão liberal, generalista ou abstrata dos direitos humanos, que ignore as lutas por reconhecimento das diferenças e igualdade de direitos de grupos sociais.

Para vencer essas e outras restrições sobre o que ensinar ao promover o letramento político, o Centro para Educação Multicultural da Universidade de Washington convidou especialistas da área para elaborar um painel com o objetivo de explicitar princípios e conceitos para o ensino da democracia que pudessem servir de guia para professores e todos aqueles que desejassem promover a democracia por meio de programas educativos. Os trabalhos, coordenados por James A. Banks, resultaram em uma publicação que busca sintetizar as principais contribuições, como bem diz seu subtítulo, para a educação de cidadãos em uma era global.

O texto Democracia e Diversidade (Banks et al, 2005) apresenta quatro princípios e dez conceitos sobre educação para a cidadania, seguidos de um checklist para que se avalie a presença desses elementos nos cursos e programas educacionais que objetivam o ensino da democracia. Os princípios foram divididos em duas seções, uma com três e outra com um princípio. Os três princípios da primeira seção dizem respeito aos direitos humanos, à interdependência derivada da globalização e ao equilíbrio entre unidade e diversidade nas relações sociais, tudo isso tanto no nível local quanto nacional e mundial. O quarto princípio é 
uma repetição do conteúdo tradicional que fala do conhecimento sobre a democracia e suas instituições, acrescido da necessidade da oferta de práticas efetivas de democracia para que o conhecimento não caia no vazio.

O caráter amplo e inclusivo dos princípios, sobretudo os da primeira seção, reflete novas direções no letramento político. Tal traço fica mais evidente nos dez conceitos que especificam os quatro princípios iniciais. É assim com o caso democracia que deve ser entendida não apenas como um regime político, democracia política, mas também um modo de organização social, democracia cultural, seguindo a proposta feita por Dewey ao falar de democracia criativa (Dewey, 1939). Outro conceito é a diversidade que vai das diferenças de classe social à religião, passando por gênero, orientação sexual, etnia, língua e necessidades especiais, que devem ser reconhecidas em uma sociedade democrática multicultural. O terceiro conceito é a globalização definida, para além dos aspectos econômicos, como interconexão e interdependência entre as pessoas e a maneira como elas vivem no mundo. O quarto conceito é o desenvolvimento sustentável, que parte da necessidade de desenvolver-se economicamente sem comprometer os recursos futuros, tal como propõe a Unesco, até chegar ao consumismo e às desigualdades da distribuição dos recursos do planeta. $\mathrm{O}$ quinto conceito é o imperialismo que abarca também seus correlatos, a exemplo de colonialismo, que devem ser estudados em suas múltiplas formas, tais como imperialismo cultural e colonialismo eletrônico, e outras relações de poder entre as nações para que se compreenda o lugar da democracia nesses contextos. O sexto conceito é a discriminação acompanhada do preconceito e do racismo que se encontram disseminados no nível interpessoal, intergrupal e institucional e ferem o princípio da igualdade, que define a democracia. O sétimo conceito é a migração que leva pessoas e grupos a se deslocarem entre países, o que demanda uma nova compreensão de cidadania. $\mathrm{O}$ oitavo conceito é a identidade e seu reverso a diversidade que aborda as várias formas de se construir o pertencimento em uma comunidade, e o reconhecimento dessas diferentes identidades é parte essencial da tolerância e respeito que devem imperar em uma sociedade democrática. O nono conceito são as múltiplas perspectivas com que cada tema ou fenômeno deve ser analisado, promovendo uma visão equilibrada que sustenta o respeito às diferenças ao mesmo tempo que favorece a construção de consensos que permitem a vida em comum. O último conceito é o jogo entre patriotismo e cosmopolitismo que busca romper com o etnocentrismo e paroquialismo e, sem deixar de valorizar a identidade nacional, compreende que somos habitantes do mesmo planeta.

Esse espectro de conteúdo que aqui se subscreve para o letramento político é certamente muito mais amplo do que vários programas costumam contemplar em seus cursos e atividades. Tal amplitude não deve servir para inibir ou restringir ações, antes abre caminhos para aprimoramentos e escolhas mais conscientes de como promover a democracia mediante diferentes possibilidades de atuação no campo do letramento político. Nesse sentido, é essencial 
que se compreenda o espírito em que princípios e conceitos foram estabelecidos acima. Trata-se menos de uma compilação acadêmica ou racionalização teórica sobre o que se deve ensinar quando se deseja ensinar democracia para aqueles que não a conhecem e mais um convite para refletir, debater e enfrentar o desafio contemporâneo de se ensinar democracia em países democráticos, conforme se pode depreender das palavras conclusivas da publicação:

\begin{abstract}
Nós oferecemos esses princípios e conceitos com a esperança de que eles ajudarão escolas em nações democráticas multiculturais a refletir a diversidade dentro de suas sociedades, a promover a unidade que é essencial para a sobrevivência de uma política democrática e ajudar estudantes a transformarem-se em cidadãos efetivos em uma comunidade global (Banks et al, 2005, p. 25).
\end{abstract}

\title{
3 Atividades: como ensinar
}

Tanto quanto os conteúdos, várias são as maneiras de se ensinar democracia, até mesmo pelas muitas abordagens que a educação oferece para o tema. Uma síntese bem conhecida das metodologias de ensino da democracia encontra-se no relatório A missão cívica das escolas (2003), patrocinado pelo Center for Information and Research on Civic Learning and Engagement e Carnegie Corporation of New York. Neste estudo, que reuniu 56 especialistas renomados na área, são listadas seis estratégias e abordagens metodológicas que comprovadamente, segundo pesquisas, colaboram para a efetivação da educação cívica: ensinar formalmente o sistema político do país; discutir temas controversos e atuais para os estudantes; levar o aluno a praticar o que aprendeu em sala de aula por meio da atuação em programas comunitários; oferecer atividades extracurriculares que envolvam o aluno no funcionamento da escola ou de sua comunidade; encorajar a participação dos estudantes na gestão escolar; e promover simulações de mecanismos e procedimentos democráticos (The Civic, 2003, p. 6).

Outro documento relevante é o relatório Strategies for Learning Democratic Citizenship, elaborado por Karlheinz Duerr, Vedrana Spajic-Vrkaš e Isabel Ferreira Martins (2000), para o projeto Educação para Cidadania Democrática do Conselho da Europa. O texto traz várias contribuições para o letramento político. Apresenta visão extensiva do ensino da democracia, não apenas em termos metodológicos, mas também em termos conceituais. Aborda as características principais, o lugar e as razões desse tipo de educação, bem como o espaço da escola, atuação docente, entre outros tópicos. Em termos de métodos e práticas, os autores distinguem três grupos que são comumente empregados no letramento político: os métodos baseados na experiência, os métodos baseados na mídia e os métodos baseados na análise. Para os métodos baseados na experiência, as estratégias consistem no encontro efetivo com outras pessoas, nos variados tipos de simulação e na produção de textos. Para os baseados na mídia, recomenda-se a leitura crítica das várias formas de mídia, incluída nessa leitura tanto os 
conteúdos, como as maneiras de comunicar e sua relação com o ensino, assim como o uso da mídia para o ensino, sobretudo aqueles recursos da mídia eletrônica e Internet. Para os com base na análise, aconselha-se a abordagem de estudos de caso, bem como a análise de textos (jornais, documentos históricos, etc ), a análise da mídia e a análise de dados estatísticos.

Uma proposta importante porque originada da análise de programas dedicados ao ensino da democracia é feita por Kahne e Westheimer (2003). Para esses autores, o ensino da democracia costuma ser bem-sucedido quando se prioriza o compromisso, as competências e as conexões democráticas. No caso do compromisso, um primeiro requisito é o exame de problemas sociais e temas controversos, pois "um sentido claro e convincente de que as coisas precisam mudar motiva e sustenta o compromisso em participar" (Kahne e Westheimer, 2003, p. 58). Outro requisito é oferecer aos alunos experiências positivas de participação democrática, cuidando para que essa experiência não leve à frustração. Para desenvolver as competências, o conselho dos estudiosos é no sentido de estimular os alunos a se engajarem em projetos reais ao mesmo tempo a participarem de simulações e oficinas que lhes forneça habilidades e conhecimentos. Com referência às conexões democráticas, é fundamental que o estudante perceba que sua ação não é individual, mas sim social. Ao conscientizar-se de como proceder, a recomendação do conselho é integrar o aluno em uma comunidade da qual possa participar ativamente.

Não é preciso verificar outros estudos para entender que há um relativo consenso sobre as práticas que devem orientar o letramento político. Democracia é um conteúdo que não pode ser apenas exposto, ele precisa ser experienciado para ser efetivo e significativo. Democracia é uma prática que precisa ser analisada e debatida para que seus valores sejam incorporados. Democracia é um conhecimento que demanda engajamento do aluno na sociedade - discussão de temas controversos, participação em atividades reais ou simuladas, análise crítica da experiência -, até porque "a tarefa da democracia será sempre a criação de uma experiência mais livre e mais humana, na qual todos participemos e para a qual todos contribuamos" (Dewey, 1939).

\section{$4 O$ contexto: as condições necessárias}

Os estudos que se preocupam com o ensino da democracia se dedicam majoritariamente aos conhecimentos e valores a serem ensinados e às formas como eles são ensinados. Todavia, o letramento político não depende apenas de conteúdos e metodologias, ainda que esses sejam aspectos essenciais de qualquer processo educativo. Também é importante entender o contexto em que a democracia é ensinada. O pressuposto é que o ensino formal da democracia é favorecido por um ambiente democrático e vice-versa, pois, como já salientamos acima, a 
democracia é um saber que precisa ser experienciado para ser efetivamente apreendido. Nessa perspectiva, conta sobremaneira a aprendizagem difusa que o ambiente democrático proporciona, ou seja, aprendemos democracia simplesmente porque a vivemos em nosso cotidiano. Dessa forma, se quisermos ser bem-sucedidos em nossos programas de letramento político, convém levar em consideração as interferências que os diferentes contextos vividos pelo estudante trazem para a sua aprendizagem.

Uma reflexão relevante sobre o assunto é feita por Biesta, Lawly e Kelly (2009) ao situar o aprendizado da cidadania na vida cotidiana de jovens observando o papel dos contextos, das relações e das disposições. Para os autores, a ideia de que a suposta crise da democracia pode ser resolvida por meio da educação dos jovens apresenta alguns problemas. O primeiro deles é que se aborda a questão em termos de indivíduos, como se a questão fosse simplesmente de aquisição pessoal de conhecimentos, valores e práticas democráticas. O segundo é que se toma a cidadania como o resultado de uma trajetória que precisa ser cumprida pelo jovem para chegar à vida adulta, com isso se perde o caráter inclusivo da democracia e se minoriza a participação dos jovens na vida política. O terceiro problema é a questão da aprendizagem. Na concepção dos autores, "os jovens aprendem no mínimo tanto sobre democracia e cidadania incluindo sua própria cidadania - por meio da participação em um conjunto de diferentes práticas que constituem suas vidas, quanto aprendem daquilo que é ensinado formalmente e oficialmente prescrito" (Biesta, Lawly e Kelly, 2009, p. 7). É por essa razão que eles defendem que o ensino da democracia precisa levar em consideração os contextos de vida dos jovens, incorporando o "caráter transversal e elusivo da aprendizagem da cidadania na vida cotidiana" (idem, p. 10, itálico dos autores).

Como sustentação de seus argumentos, os autores apresentam os resultados de uma pesquisa realizada na Inglaterra com 29 jovens entre 13 e 20 anos. O primeiro achado da pesquisa é que o contexto tem realmente grande influência sobre a educação para a democracia, ou seja, se o jovem se movimenta em contextos diferentes, diferentes serão as oportunidades para a sua aprendizagem da cidadania. Outro achado é que o peso do contexto é mediado pelas relações que se estabelecem entre eles, pois o jovem pode transferir experiências positivas de um contexto para outro ou as experiências positivas de um contexto podem superar as de outro não tão favorável à aprendizagem da cidadania. Um terceiro achado é que, para além do contexto e das relações entre eles, contam no processo as atitudes ou disposições do jovem em relação aos acontecimentos que está vivendo. Uma posição reflexiva sobre a experiência tem mais peso do que uma meramente hedonística. Frente esses dados, a conclusão dos autores é que, para além do ensino formal de democracia que os jovens podem ter na escola, eles "aprendem das oportunidades de participação, ação e reflexão que são oferecidas pelas práticas e comunidades em sua vida quotidiana" (idem, p. 21). 


\section{Letramento político: uma posição}

Dos textos que lemos acima, é possível concluir que não há um conteúdo acabado sobre democracia. Aprendemos todos os dias como ser democratas. Aprendemos que as prioridades de hoje não são as de ontem, tampouco serão as de amanhã. Algumas comunidades, por exemplo, sentirão necessidade de enfatizar a liberdade se enfrentam posições sociais autoritárias; outras poderão ver na igualdade um elemento fulcral sobretudo se há discriminação entre os grupos sociais, todos sabendo que liberdade e igualdade são características inerentes ao viver em democracia. São os princípios, mais que os conceitos, que devem orientar os conteúdos do ensino da democracia. Não há metodologia nem estratégia única para o letramento político. Sabemos que a exposição de conhecimentos e valores democráticos precisa ser perpassada por análises e experiências concretas para que a aprendizagem seja bem-sucedida. Não há disciplina escolar, projeto ou programa de letramento político que deva ignorar os contextos em que serão experienciados pelos alunos, pois a democracia é um aprendizado que se faz na prática e pela prática.

Há, assim, uma síntese possível sobre a condução de eventos de letramento político, seja na escola, seja em outros contextos, que deixam os seus praticantes relativamente seguros quanto aos resultados a serem obtidos. Todo letramento político compreende a disseminação de conhecimentos sobre a democracia, governo democrático, organização política, instituições e seu funcionamento, a Constituição, direitos e deveres da vida em comum, ou seja, conhecimento sobre como a distribuição de poder se organiza e funciona. Todo letramento político só se efetiva quando promove práticas que tratam das habilidades e competências necessárias ao desenvolvimento do pensamento crítico, à participação decisória, à resolução pacífica de conflitos, ao viver em uma comunidade em que se reconhece igualmente o direito de cada um, em que há respeito pelo outro. Todo letramento político deve ser é guiado por valores ou atitudes que sustentam e favorecem a vida democrática, tais como tolerância, diversidade nas relações sociais, interdependência, igualdade, equidade e liberdade.

A exposição que fizemos acima de reflexões e propostas sobre conteúdos, metodologias e contextos teve por objetivo indicar alguns consensos, construídos por meio de pesquisas e debates intensos, sobre uma pedagogia do letramento político. A ideia foi apresentar as falas de uma conversa que interessa a todos que atuam no campo do ensino da democracia. Nesse sentido, mais do que um improvável estado da arte, as questões delineadas acima para o letramento político são quase provocações, um convite ao debate sobre o que ensinar, como ensinar e em que condições se deve ensinar a democracia. 


\section{Referências}

ABREU, Vanessa Kern; INÁCIO FILHO, Geraldo. A educação moral e cívica - doutrina, disciplina e prática educativa. Revista HISTEDBR on-line, Campinas, n. 24, p. 125 -134, dez. 2006. Disponível em: http://www.histedbr.fae.unicamp.br/art11_24.pdf .Acesso em: 20 mar. 2010.

ARAÚJO, Ulisses F. Educação comunitária e a construção de valores de democracia e cidadania. "Paper" apresentado na 33rd Annual Conference of the Association for Moral Education New York, 15-18/11/2007. Disponível em: http://www.each.usp.br/uliarau/textos/PAPERAME2007-def.pdf. Acesso em: 20 abr. 2011.

BANKS, J. et al. Democracy and diversity. Principles and concepts for educating citizens in a global age. Seattle, Centre for Multicultural Education, University of Washington, 2005. Disponível em: <http://www.depts.washington.edu/centerme/DemDiv.pdf >. Acesso em: 20 mar. 2010.

BIESTA, Gert; LAWLY, Robert;KELLY, Narcie. Understanding young people's citizenship learning in everyday life: the role of contexts,relationships and dispositions. Education, Citizenship and Social Justice, v. 4, v. 1, p. 5-24, 2009. DOI: 10.177/1746197908099374.

CARVALHO, José Sérgio et al. Formação de professores e educação em direitos humanos e cidadania: dos conceitos às ações. Educação e Pesquisa, São Paulo, v. 30, n.3, p. 435-445, set./dez. 2004.

COSSON, Rildo. Escolas do legislativo, escola de democracia. Brasília: Câmara dos Deputados, Edições Câmara, 2008.

COSSON, Rildo. Letramento político: por uma pedagogia da democracia. Cadernos Adenauer, XI, n. 3, p. 25-36, 2010.

CRICK, B. Education for citizenship and the teaching of democracy in schools. Final report of the Advisory Group on Citizenship. London: Qualifications and Curriculum Authority (QCA), 1998. Disponível em:

<www.qca.org.uk/libraryAssets/media/6123_crick_report_1998.pdf>. Acesso em: 10 abr. 2007.

DEWEY, J. Creative Democracy - The task before us. 1939. Disponível em

<http://www.beloit.edu/ pbk/dewey.html>. Acesso em: 5 set. 2007.

FERREIRA MARTINS, Isabel; DUERR, Karlheinz;SPAJIC-VRKAŠ, Vedrana. Strategies for Learning Democratic Citizenship. DGIV/EDU/CIT, Conselho da Europa, Estrasburgo, 2000. Disponível em:<www.coe.int/t/dg4/education/edc/Source/Pdf/Documents/2000_16_Strategies4LearningED C.pdf>. Acesso em: 20 ago. 2007.

KAHNE, Joseph;WESTHEIMER, Joel. Teaching democracy: what schools need to do. Phi Delta Kappan, v. 85, n.1, p. 34-66, set. 2003.

THE CIVIC mission of schools. A report from Carnegie Corporation of New York and CIRCLE: The Center for Information and Research on Civic Learning and Engagement. 2003. Disponível em: http://civicmissionofschools.org/site/campaign/overview/cms report.html. Acesso em: 28 abr. 2007.

Artigo recebido em: 13/09/2011

Artigo aceito para publicação em: 27/09/2011 